Subscriber access provided by Universidad de Alicante

Process Systems Engineering

\title{
Economic and Environmental Analysis of the Hydrothermal Liquefaction Process of Animal by-products
}

Antonio Marcilla, Juan A. Labarta, Milagros León, and Angela N. Garcia

Ind. Eng. Chem. Res., Just Accepted Manuscript • DOI: 10.1021/acs.iecr.9b04335 • Publication Date (Web): 19 Nov 2019

Downloaded from pubs.acs.org on November 25, 2019

\section{Just Accepted}

"Just Accepted" manuscripts have been peer-reviewed and accepted for publication. They are posted online prior to technical editing, formatting for publication and author proofing. The American Chemical Society provides "Just Accepted" as a service to the research community to expedite the dissemination of scientific material as soon as possible after acceptance. "Just Accepted" manuscripts appear in full in PDF format accompanied by an HTML abstract. "Just Accepted" manuscripts have been fully peer reviewed, but should not be considered the official version of record. They are citable by the Digital Object Identifier (DOI@). "Just Accepted" is an optional service offered to authors. Therefore, the "Just Accepted" Web site may not include all articles that will be published in the journal. After a manuscript is technically edited and formatted, it will be removed from the "Just Accepted" Web site and published as an ASAP article. Note that technical editing may introduce minor changes to the manuscript text and/or graphics which could affect content, and all legal disclaimers and ethical guidelines that apply to the journal pertain. ACS cannot be held responsible for errors or consequences arising from the use of information contained in these "Just Accepted" manuscripts. 


\title{
Economic and Environmental Analysis of the
}

\section{Hydrothermal Liquefaction Process of Animal by- products}

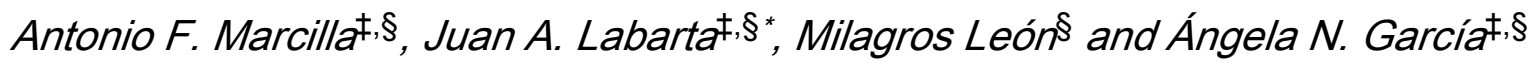 \\ ‡Department of Chemical Engineering, University of Alicante, PO 99, E-03080 \\ Alicante, Spain.
}

§Institute of Chemical Process Engineering, University of Alicante, PO 99, E-03080

Alicante, Spain.

Keywords: Hydrothermal Liquefaction, Life Cycle Assessment, Animal by-Products,

Waste treatment, Economic evaluation, ReCiPe methodology, Ecoinvent Database. 


\section{ABSTRACT}

Animal by-products consist in parts of animals or products of animal origin not intended for human consumption. The recovery and treatment of this kind of waste is a challenging problem due to their high volume and heterogeneous nature. In this sense, previous studies have shown that hydrothermal liquefaction (HTL) can be a viable technology for transforming these wastes into a valuable biofuel. In this paper a comparative preliminary analysis of costs and resource consumption (water and energy) between HTL and pyrolysis for this type of by-products has been performed. The results indicate that HTL with aqueous phase recycled is the most favorable treatment. Additionally, a life cycle assessment (LCA) has been developed for the selected option, including the combustion of the liquid biofuel obtained. Gas combustion, HTL gas phase, aqueous phase, solid fraction and electricity demanded have been the five burdens analyzed to evaluate the corresponding environmental impacts and damage categories at different levels. Thus, at the aggregated endpoint level the analysis indicates that the use of the biofuel obtained from HTL produces a 
strong reduction in the $\mathrm{CO}_{2}$ emissions per kWh of electricity produced comparing with fossil fuel. 


\section{INTRODUCTION}

Regarding biomass waste, animal by-products (ABPs) are a heterogeneous type of waste that covers a wide spectrum of origins, from slaughterhouse refuses to house garbage. It is important to remark that the water content of this type of residues is high (between $40-70 \%{ }^{1,2}$ ).

By-products included in this group are considered hazardous when they come from ill animals or viscera (categories 1 and 2), being the landfill or co-combustion their last ending. In the case of non-risk wastes, as the ones analysed in the present paper, coming from non-commercial residues in production plants or slaughterhouses (category 3) the usual treatment technology is the rendering process, where the raw material is heated up to $406 \mathrm{~K}$ at 3 bars of pressure. Examples of this kind of non-risk wastes are meat out of specifications and rejected by producers, skins, hooves, horns, carcases, etc. that have passed the corresponding inspections and show no signs of disease communicable to humans or animals. The typical results of their treatment are on one hand, the fat recovery 
and on another, the processed animal protein and bones useful for animal consumption.

The international interest in exploring other types of valorization, such as the extraction of high value oils, protein recovery and production of liquid biofuels ${ }^{3}$ has increased. This paper is centred in the third of these aspects. Traditionally, the biomass used as source of liquid fuels has been lignocellulosic biomass and the thermal process which leads to this goal is the pyrolysis. More recently, the hydrothermal liquefaction ( $\mathrm{HTL}$ ) process has been reconsidered to be used with high water content biomass, being microalgae culture one of the raw materials more widely studied. To the best of our knowledge, few pyrolysis and HTL studies using ABPs can be found. As example, some references analyse samples of bones and meat residues ${ }^{4-6}$ as well as cattle manure ${ }^{7}$. In all the cases, different operating conditions are analysed to reach the maximum biofuel yield. However, aspects such as the environmental problems derived from the massive use of fossil fuels, the high volume of ABPs generated annually (over 20 million tons in the European Union ${ }^{8}$ ) and the development of integrated systems such as biorefineries to obtain products 
and energy force to study new ways of inertization, treatment and valorization of ABPs as well as the feasibility of using them as new source of chemicals and renewable energy.

In this context, pyrolysis and hydrothermal liquefaction process (HTL) would be two technically feasible alternatives for the thermal conversion of these wastes and the generation of liquid fuels, since combustion process produces energy released directly in the process, gasification optimizes gas fraction and biochemical treatments are more appropriated to produce biogas and derivatives from fermentation.

Pyrolysis and HTL show significant differences in the operational conditions and in the fraction yields generated. In the case of pyrolysis, the process temperature to optimize the liquid biofuel fraction is around $773 \mathrm{~K}$ at 1 bar of pressure, obtaining also a significant gas yield. One of the disadvantages of this methodology is the necessity of drying the sample before the process, which involves high energy consumption (around $66 \%$ of the total energy requirements). HTL process avoids the initial drying step, since this technology uses water under sub-critical conditions as 
extractive and reactive environment. This technique works at low temperature but, on the contrary, it needs high pressure. Under these conditions, a solid fraction and two liquid phases are generated (aqueous and organic phases), being the gas volume obtained very low.

The review of the literature on HTL processes compared to other thermal ones ${ }^{9-18}$, such as pyrolysis, highlights the necessity of performing individual analyses for each system, since the differences in the raw materials used, the boundaries of the system analyzed and the operating conditions studied make difficult the extraction of general conclusions. Thus, for example, some authors ${ }^{17}$ indicated that $\mathrm{HTL}$ is better option than pyrolysis for the bio-oil production from oil palm empty fruit bunch. However, other researchers ${ }^{13}$ considered that a dry step and combustion process of olive mill waste is a more environmentally friendly valorization than the hydrothermal carbonization process. According to literature ${ }^{10}$, the catalytic hydrothermal gasification of aqueous phase obtained in the HTL of algal biomass gives better results than its re-use in the pond growth. Consequently, the first objective of the present work is to compare three possible scenarios of HTL -i.e.: i) $80 \%$ initial water 
content, ii) $60 \%$ initial water content and iii) water recycling- with pyrolysis and to select the most favorable option from the point of view of water and energy consumption. Then to develop a Life Cycle Assessment (LCA) of the selected option in order to characterize the process from the point of view of its environmental impact and influence on climate change.

\section{EXPERIMENTAL SECTION}

The experimental data (yields and composition) used in this paper are based on experimental results obtained at lab scale in two different systems: fluidized bed reactor for pyrolysis and batch reactor for HTL process. This second system was used in a wide study, whose results were useful to select the optimal operating conditions of an ABP HTL process $^{19}$ and to build a HTL pilot plant, with a screw reactor, for this type of material.

\subsection{Material}

The raw material used is $\mathrm{ABP}$ (category 3), supplied by a local rendering company and composed by raw waste from porcine and bovine origin, with a moisture percentage of $43 \%$. The material was ground until a mesh size of $0.710 \mathrm{~mm}$. 


\subsection{Experimental system}

2.2.1. Pyrolysis system. The reactor used is a vertical reactor $(71 \times 5.8 \mathrm{~cm})$ heated by a cylindrical oven, with a feed hopper at the top, a carrier gas $\left(N_{2}\right)$ entry at the bottom and a lateral exit for the volatiles. This exit is connected to a collecting line with two glass traps to condense the volatiles evolved and a tedlar bag to collect the gas fraction. Solid residue remains in the reactor until its discharge.

Before starting the experiment, about $2 \mathrm{~g}$ of dried raw material were placed in the feed hopper purged with $N_{2}$, the reactor was heated up to $525^{\circ} \mathrm{C}$ and the carrier gas $\left(\mathrm{N}_{2}\right)$ flow was adjusted to $700 \mathrm{ml} / \mathrm{min}$. At this moment, the sample is dropped into the reactor and the volatiles evolved began to be collected. More details of this system can be found elsewhere 20 .

2.2.2. HTL system. A cylindrical reactor $(8.5 \times 4.5 \mathrm{~cm})$ electrically heated and prepared to withstand high pressure was used. During the experiment, the reactor was sealed and the outlet valves closed to keep the pressure inside. When the run is finished, the valves are opened and gas and liquid fractions coming from the reactor 
were collected in the traps (liquid phases) and tedlar bag (gas fraction). Solids remain in the reactor until its discharge.

Before starting the experiment around $80 \mathrm{~g}$ of sample (raw material + distilled water) were placed in the reactor which was purged, sealed and pressurised at 28 bar. The reactor was heated up to $250^{\circ} \mathrm{C}$. Due to the temperature, the vapour pressure of the water in the reactor and the gas fraction generated, the pressure inside the reactor increased up to around 100 bar. When the run was finished, the reactor was cooled down and pressure decreased simultaneously. Outlet valves were then opened and the products obtained were collected. More details of this system can be found elsewhere $^{19}$.

In order to study the recycling of the aqueous phase in the process, four consecutive experiments were performed where the aqueous phase of each one was added in the following run, instead of using fresh water each time.

Table 1 shows the operational parameters selected in the pyrolysis and HTL processes studied. The processes studied as well as the operating conditions used have been selected to maximize the organic phase (biofuel) obtained. 
Table 1. Operational parameters of thermal processes studied.

\begin{tabular}{|l|c|c|}
\hline & HTL & Pyrolysis \\
\hline Water content in the reactor $(\%)$ & $60 / / 80$ & 0 \\
\hline P raw material $(\mathrm{atm})$ & 1 & 1 \\
\hline T raw material $\left({ }^{\circ} \mathrm{C}\right)$ & 25 & 120 (after drying) \\
\hline T reactor $\left({ }^{\circ} \mathrm{C}\right)$ & 250 & 525 \\
\hline P reactor $($ atm) & 100 & 1 \\
\hline Residence time of solids $(\mathrm{min})$ & 29 & 10 \\
\hline Pre-treatments & grinding & grinding + drying \\
\hline
\end{tabular}

\subsection{Analytical methods}

The fractions obtained were measured and their yields were calculated. Different analyses were performed to characterize them:

Gas fraction was analyzed by gas chromatography, GC-FID for hydrocarbons and GC-FID with methanizer for carbon oxides. Liquid phases were analyzed by gas chromatography with mass spectrometry (GC-MS). For the analysis, the organic phase was diluted in n-hexane and the aqueous phase in isopropanol. For quantification of gas and liquid compounds, different standards of known concentration were injected. 
A thermogravimetric analysis (TG/DTG) was also performed to characterize the solid and liquid fractions. The analysis was developed in the temperature range $25-800^{\circ} \mathrm{C}$ at $10^{\circ} \mathrm{Cmin}^{-1}$, under inert atmosphere $\left(\mathrm{N}_{2}\right)$.

More details of the analysis conditions can be found elsewhere ${ }^{2,19}$

\subsection{Experimental results}

Table 2 shows the yields of the different fractions obtained in both systems.

Table 2. Yield of fractions obtained.

\begin{tabular}{|l|c|c|}
\hline & $\begin{array}{c}\text { HTL } \\
\text { (\% w/w, dry-basis) }\end{array}$ & $\begin{array}{c}\text { Pyrolysis } \\
\text { (\% w/w, dry-basis) }\end{array}$ \\
\hline Gas & 1.1 & 18.4 \\
\hline Biofuel & 58.2 & 53.4 \\
\hline $\begin{array}{l}\text { Aqueous } \\
\text { phase }\end{array}$ & 19.6 & - \\
\hline Solid & 15.4 & 28.1 \\
\hline
\end{tabular}

Information about the components of the gas and liquid fractions obtained in the HTL process and identified by gas chromatography as well as the water/organics/solids ratios deduced for each fraction from the TG/DTG results has been included in the Supporting Information (Appendix 1). 


\section{COMPARATIVE ANALYSIS. SELECTION OF ALTERNATIVES}

The initial study to select the best alternative for thermal recycling of ABPs has been

developed according to the following steps:

- Definition of the processes to be studied

- Comparison of the external services consumption

- Comparison of the total annualized costs

The study presented scales the experimental results previously obtained up to a continuous process at industrial scale, considering a raw material flow of $5000 \mathrm{~kg} / \mathrm{h}$ of ABPs. A plant with this capacity could treat the waste generated in a standard city of medium-size, with a population of 300.000 inhabitants.

\subsection{Process description}

Figures 1 and 2 show the scheme of the thermal processes selected. Figure 1 corresponds to the one whose core is the HTL technology and Figure 2 corresponds to the pyrolysis technology. Blocks and lines in black represent basic elements in the processes, while the optional ones are remarked in blue dotted lines. 
In the HTL process, a screw reactor is proposed since this type of reactor facilitates the flow of wet heterogeneous solids. In the pyrolysis process, an inert fluidized bed reactor has been selected, which facilitates the heat transfer to the sample and it is a very common reactor used in pyrolysis processes of dry samples ${ }^{21}$.

In addition to using different reactors, Figures 1 and 2 show also some significant differences between both processes. On one hand, the fact of working at high pressure in the HTL technology forces to a semi batch discharge of the products in the system. The collection lines and tanks of the different fractions must be duplicated in order to keep the pressure inside the reactor while products are discharged. On the other hand, as commented on previously, pyrolysis process requires a feed drying step to remove the initial sample humidity. If this previous step were omitted, the corresponding energy to evaporate the water should be anyway supplied the fluidized bed reactor.

Additionally, the pyrolysis process needs an additional flow of inert gas that works as carrier and fluidizing gas. The best option considered has been to produce $\mathrm{N}_{2}$ in situ from air in an auxiliary plant ${ }^{22}$ (the oxygen produced could also be sold). 


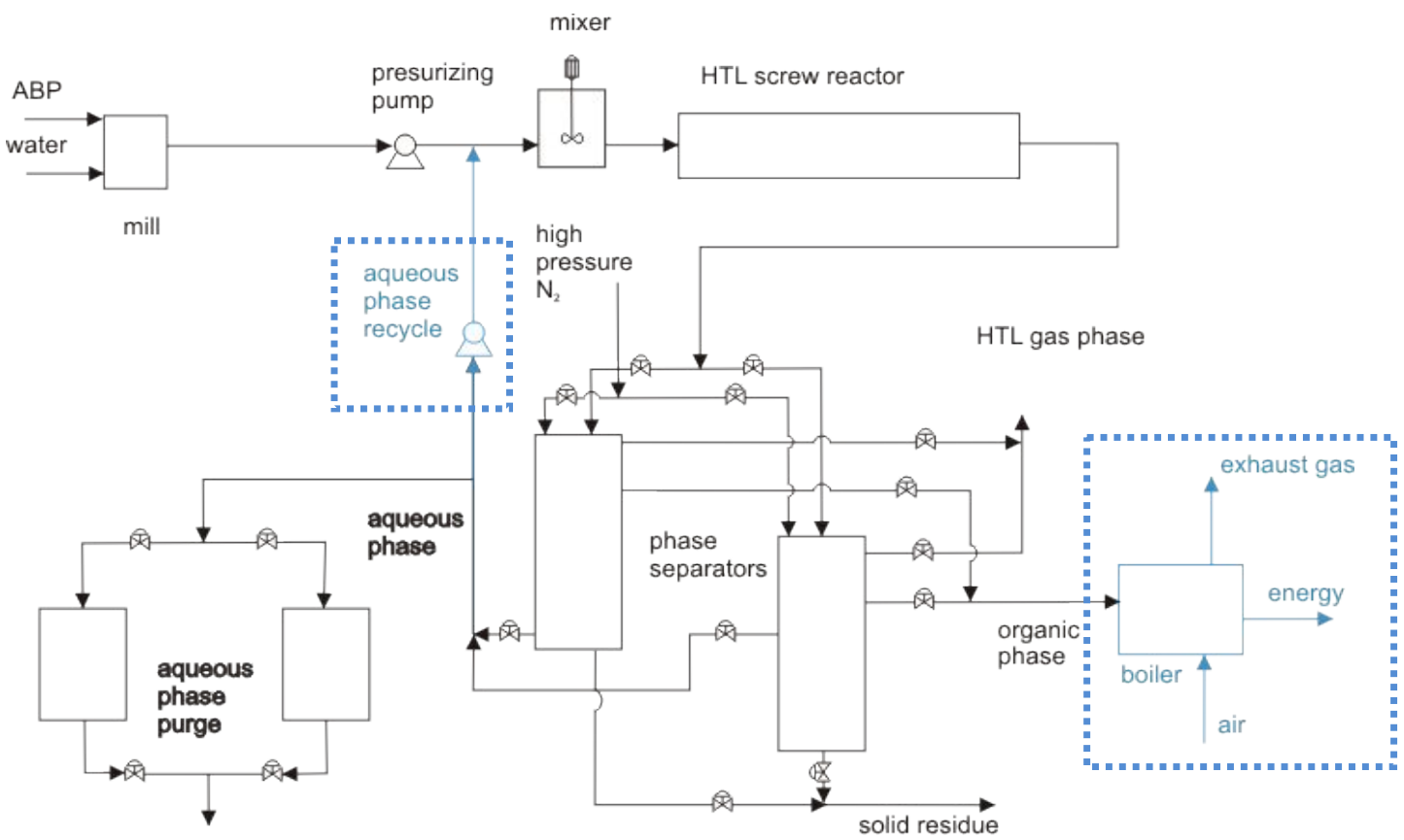

Figure 1. Scheme of a continuous HTL process

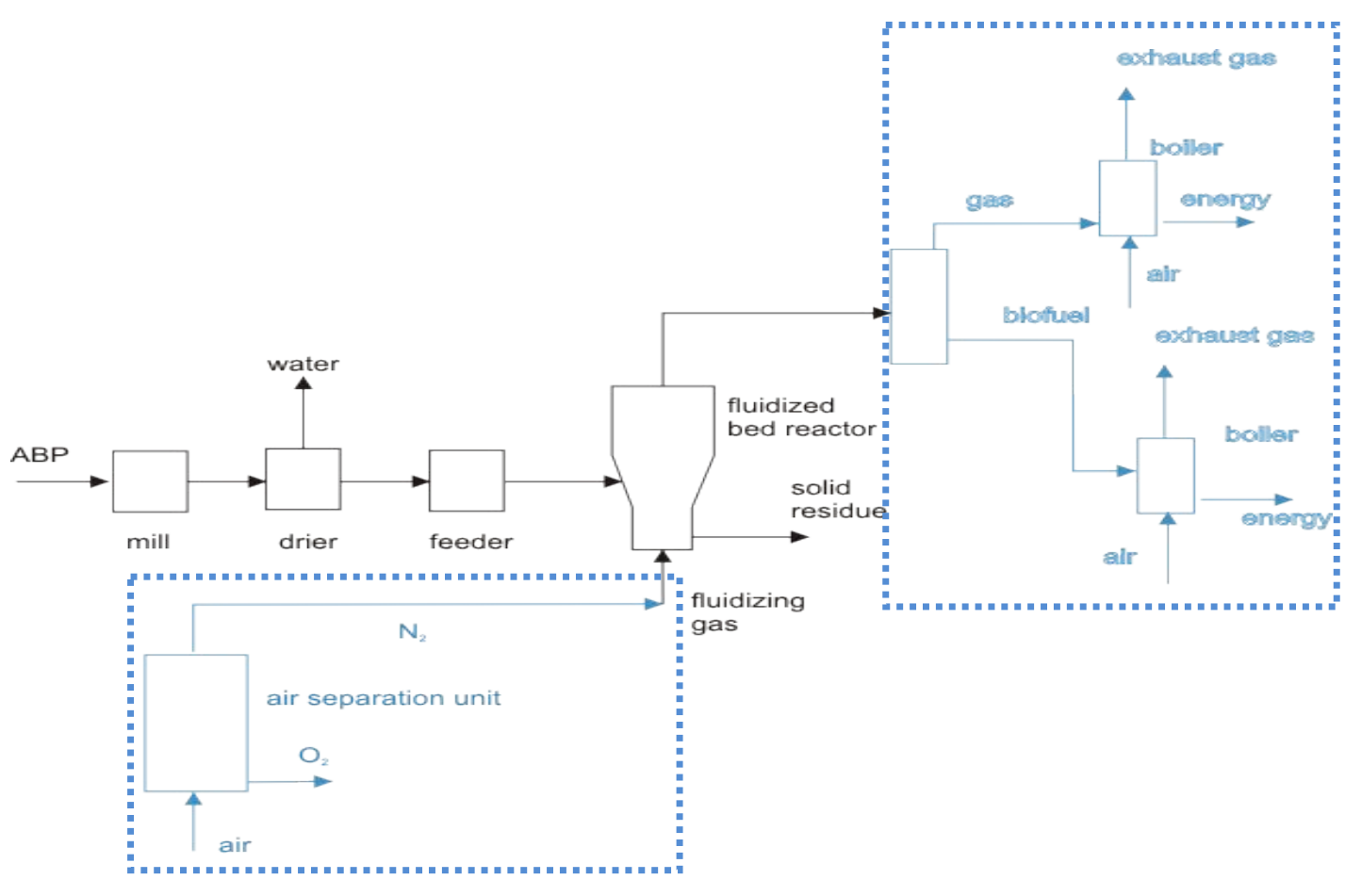

Figure 2. Scheme of a continuous pyrolysis process 
As commented on before, the HTL process needs the presence of water as extractive solvent. In the case of ABPs, it has been experimentally tested that when the humidity of the raw material is around $40 \%$, the water content in the sample is not enough for carrying out the HTL process satisfactorily ${ }^{19}$. This fact is due to the formation of foams that makes difficult the scale-up of the process, being necessary the increase of the water ratio. From data found in literature, a water content of $80 \%$ was initially fixed ${ }^{23}$. However, it has been experimentally checked that the ABP HTL process is technically viable and easy to handle with water content above $60 \%{ }^{19}$.

The operational parameters selected in the HTL and pyrolysis processes as well as data. related to yields and flows necessary for developing this study were those obtained in batch reactors and scaled-up for a feed mass flow of $5000 \mathrm{~kg} / \mathrm{h}$ (Appendix 2 in Supporting Information).

In both processes, three fractions are formed: gas, liquid and solid. In the case of $H T L$, the liquid fraction presents two phases: aqueous and organic. Except the aqueous phase (obviously with high water content), the rest of fractions are susceptible of being burnt. For this reason, it is expected that both processes lead to 
a similar energy recovery rates, consequently this aspect not allowing by itself prioritizing one process over another.

\subsection{External service consumptions}

Water and energy are the external resources more highly consumed in both processes, as it is deduced from Figures 1 and 2. A balance of these items has been performed to obtain a first vision about which one of these processes can be more interesting. Calculations have been performed according to the following considerations:

Mill and mixer: energy demanded has been estimated from data obtained from commercial information about industrial mills ${ }^{24}$ and mixers ${ }^{25}$.

Dryer: energy calculated considering sensible heat of the raw material and vaporization latent heat of water.

Pump: energy calculated considering the pressure increment in the pump (efficiency estimated $=85 \%$. 
Reactor: energy calculated considering sensible heat of the feed and its pyrolysis enthalpy $\left(400 \mathrm{~kJ} / \mathrm{kg}^{26}\right)$ for the pyrolysis process. In the HTL system, the heat requirements have been calculated as the heat needed for heating the sample as well as the water and the HTL enthalpy.

Energy needed for biomass feeder (for the pyrolysis case): a screw has been selected to transport the feed into the pyrolysis reactor. The value of the energy consumed is very low comparing with the energy consumed in the reactor. Thus, it has been included in the reactor value.

Gas supply system (for the pyrolysis case): a blower has been selected, since the pressure drop estimated is lower than 1 bar. The energy consumed has been included with that of the $\mathrm{N}_{2}$ production plant.

Condenser and nitrogen production (for the pyrolysis case): a cooling tower is also needed to cool down the cooling water used as refrigerant. The flow of water fed as refrigerant has been estimated as the one evaporated in the cooling tower.

Appendix 3 (Supporting Information Section) shows the calculations performed to estimate the values of the water and energy consumption in both processes. Table 3 
shows these values. As can be observed, the consumption of both resources in the $\mathrm{HTL}^{\mathrm{A}}$ (working with a water content of $80 \%$ ) is higher than that in the pyrolysis process, due to the large flow of additional water used in the HTL system and consequently, the large amount of energy required to increase its temperature and pressure. Moreover, the HTL equipment cost will also be more expensive than that of pyrolysis, due to the high pressures that it must support. Therefore, with these considerations, the initial choice would be undoubtedly the pyrolysis process.

Table 3. Water and energy consumptions in HTL and pyrolysis processes referred to a feed flowrate of $5000 \mathrm{~kg} / \mathrm{h}$ of ABPs.

\begin{tabular}{|c|c|c|c|c|c|}
\hline Flowrate & Item & Pyrolysis & $\mathrm{HTL}^{\mathrm{A}}$ & $\mathrm{HTL}^{\mathrm{B}}$ & $\mathrm{HTL}^{\mathrm{C}}$ \\
\hline \multirow{4}{*}{$\begin{array}{l}\text { Water } \\
\text { (kg/h) }\end{array}$} & Water added & --- & 9250 & 2074 & 0 \\
\hline & Condenser & 1409 & --- & --- & --- \\
\hline & $\begin{array}{ll}\mathrm{N}_{2} & \text { plant } \\
\text { production } & \end{array}$ & 555 & --- & --- & --- \\
\hline & TOTAL & 1964 & 9250 & 2074 & 0 \\
\hline \multirow{7}{*}{$\begin{array}{l}\text { Energy } \\
(\mathrm{kWh} / \mathrm{h})\end{array}$} & Mill & 69 & 69 & 69 & 69 \\
\hline & Mixer & --- & 3 & 3 & 3 \\
\hline & Dryer & 1651 & --- & --- & --- \\
\hline & $\begin{array}{l}\text { Pump (high } \\
\text { pressure) }\end{array}$ & --- & 46 & 23 & 16 \\
\hline & Reactor & 702 & 3147 & 1272 & 839 \\
\hline & $\begin{array}{ll}\mathrm{N}_{2} & \text { plant } \\
\text { production } & \end{array}$ & 270 & --- & --- & --- \\
\hline & $\begin{array}{l}\text { Pump for aqueous } \\
\text { phase recycling }\end{array}$ & --- & --- & --- & 3 \\
\hline
\end{tabular}




\begin{tabular}{|l|l|l|l|l|l|}
\hline & TOTAL & 2692 & 3265 & 1367 & 930 \\
\hline
\end{tabular}

However, as was commented on previously, it was experimentally checked that ABP HTL process could be also developed with a water content of $60 \%$. Table 3 includes the resources (water and energy) consumption corresponding to this percentage of water content $\left(\mathrm{HTL}^{\mathrm{B}}\right)$. As can be seen, under this condition, the water consumption is comparable to that of pyrolysis, the energy value being lower.

In order to minimize service consumption, a third scenario has been included in the comparison, where the aqueous phase formed in the HTL process is recycled into the reactor, avoiding the input of fresh water into the system (except the own humidity of the initial raw material) and purging out only the required aqueous phase amount to avoid any accumulation. According to the experimental results obtained ${ }^{19}$, the recycled aqueous phase HTL process, with a water content of $60 \%$ in the system is viable. Under these circumstances, the biocrude yield diminishes around $15 \%$ respect to the run with fresh water and the recycled aqueous phase is saturated in organic compounds with a mass fraction of around $18 \%$. The reduction of the biocrude is not a handicap vs. the advantage of reducing water and energy 
consumption. In other cases, with a different raw material, the presence of specific organics in the aqueous phase recycled improves the biocrude yield, as it has been previously shown working with lignocellulosic biomass ${ }^{27}$. Table 3 also includes the values corresponding to this scenario $\left(\mathrm{HTL}^{\mathrm{C}}\right)$. As it is observed, this option is much more beneficial than the previous ones.

According to these results, it seems evident that, from the point of view of the consumption of the resources most directly affected by the thermal processes studied, the best thermal treatment for obtaining biofuel from this type of $A B P$ residues is the HTL process with recycling of aqueous phase. Therefore, and in order to confirm these results an economic analysis must be done, as next step, to know if the alternative selected is the most economical one or, on the contrary, its cost is less favorable than that of pyrolysis.

\subsection{Total annualized cost analysis}

The economic analysis of the pyrolysis process as well as the HTL with aqueous phase recycled has been performed. The total annualized cost (TAC) calculated comprises the annualized capital costs (ACC) of the equipment (including the cost of 
the reactor, heat exchanges, mill and pumps, etc.) and the annual operational costs

$(\mathrm{AOC})$ associated (eq 1):

$$
T A C=\sum_{j}^{\text {Equipmet }}\left(A C C_{j}+A O C_{j}\right)=\sum_{j}^{\text {Equipmet }}\left(C C_{j} \cdot c r f+A O C_{j}\right)
$$

in which crf represents the capital recovery factor ${ }^{28}$ according to eq 2 :

$$
c r f=\frac{i r(1+i r)^{n}}{(1+i r)^{n}-1}
$$

where ir is the fractional interest rate per year (10\%) and $n$ is the number of useful years of the unit junder consideration (considered in general 8 years).

The capital costs of the equipments $\left(\mathrm{CC}_{\mathrm{j}}\right)$ have been estimated by applying scale factors to the costs of the experimental pilot plant developed. The operational costs for both systems have been estimated considering the services used in each process and the energy and water prices for industrial consumers in Spain $(0.1098$ $€ / \mathrm{kWh}$ and $0.00192 € / \mathrm{kg}$, respectively $\left.{ }^{29,30}\right)$.

The cost values estimated are shown in Table 4. As can be seen, the capital cost of the system needed is higher in the case of the HTL process due to the high-pressure equipment required in this technology, as commented on before. However, when 
capital costs are annualized and added to operational costs, the weight of the capital costs are minimised and the TAC of the HTL configuration, with recycled aqueous phase, to obtain biofuel from ABPs is around $42 \%$ of the one corresponding to the pyrolysis process, showing its great potential.

Table 4. Cost comparison of the HTL and pyrolysis processes.

\begin{tabular}{|c|c|c|c|c|}
\hline \multirow[b]{2}{*}{ Equipment } & \multicolumn{2}{|c|}{ HTLC } & \multicolumn{2}{|c|}{ Pyrolysis } \\
\hline & capacity & costs $(€)$ & capacity & costs $(€)$ \\
\hline Mill+ mixer & $1.4 \mathrm{~m}^{3}$ & 97000 & $2.7 \mathrm{~m}^{3}$ & 60000 \\
\hline Pump (high pressure) & $5000 \mathrm{~kg} / \mathrm{h}$ & 270000 & - & - \\
\hline Pump (aqueous phase recycling) & $3748 \mathrm{~kg} / \mathrm{h}$ & 125000 & - & - \\
\hline Dryer & - & - & $2.7 \mathrm{~m}^{3}$ & 60000 \\
\hline Reactor & $2.2 \mathrm{~m}^{3}$ & 450000 & $3 \mathrm{~m}^{3}$ & 330000 \\
\hline Condenser & - & - & $12 \mathrm{~m}^{2}$ & 30000 \\
\hline $\begin{array}{l}\text { High-pressure container for product (2 } \\
\text { units) }\end{array}$ & $2.6 \mathrm{~m}^{3} /$ unit & 160000 & - & - \\
\hline $\begin{array}{l}\text { High-pressure container for aqueous phase } \\
(2 \text { units })\end{array}$ & $\begin{array}{c}0.54 \\
\mathrm{~m}^{3} / \text { unit }\end{array}$ & 50000 & - & - \\
\hline Container for liquid fraction (2 units) & - & - & $1 \mathrm{~m}^{3} /$ unit & 10000 \\
\hline Container for solid fraction (2 units) & - & - & $0.5 \mathrm{~m}^{3} /$ unit & 5000 \\
\hline Auxiliary plant $\left(\mathrm{N}_{2}\right)$ & - & - & $\begin{array}{c}108 \\
\mathrm{kgN}_{2} / \mathrm{h}\end{array}$ & 30000 \\
\hline Valves, pipes, instrumentation and control & - & 150000 & - & 15000 \\
\hline CAPITAL COSTS $(€)$ & \multicolumn{2}{|c|}{1302000} & \multicolumn{2}{|c|}{540000} \\
\hline OPERATIONAL COSTS (€/h) & \multicolumn{2}{|c|}{102.0} & \multicolumn{2}{|c|}{299.4} \\
\hline TOTAL ANNUALIZED COSTS (€/year) & \multicolumn{2}{|c|}{1059700} & \multicolumn{2}{|c|}{2496768} \\
\hline
\end{tabular}

\section{LIFE CYCLE ASSESSMENT METHODOLOGY}


According to the previous analysis, HTL with recycled aqueous phase is the most beneficial process to obtain bio-fuel from ABPs, from an economic as well as from the consumption of services, such as water and energy, point of view. To complete this analysis, the Life cycle assessment ${ }^{31}$ (LCA) of the HTL with recycled aqueous phase has been carried out. According to the standards ${ }^{32,33}$, the LCA includes the following steps:

- scope definition of the study defining the corresponding boundaries of the system,

- determination of the life cycle inventory (LCI) with all the inlet and outlet streams of the system (environmental burdens),

- life cycle impact assessment (LCIA) to transform the previous burdens into environmental impacts, and - interpretation of the results obtained.

Thus, this analysis will allow to develop a detailed study of the damage categories and environmental impacts associated to this process and also to determine what aspect(s) should be improved to become the process more sustainable. 


\subsection{Model and System boundary}

The functional unit used in this work to build the LCA model has been 1 metric ton of ABP to be processed. The system boundary of this study covers the configuration of the $\mathrm{HTL}$ process shown in Figure 3, including the aqueous phase recycling and the combustion of the obtained products.

As was commented on previously, although the biofuel is the most interesting fraction in this process, solids and gas fraction are also susceptible of being burnt. The major calorific value is obviously shown by the biofuel (around $35 \mathrm{MJ} / \mathrm{kg}$ ) which is also the major fraction. Solids show a very low calorific value (around $2 \mathrm{MJ} / \mathrm{kg}$ ) because of its high percentage of ash. The yield of the gas fraction generated is very low, mainly formed by $\mathrm{CO}_{2}$, and its energy use is not interesting. However, its combustion could be beneficial to reduce the environmental impacts of its emission.
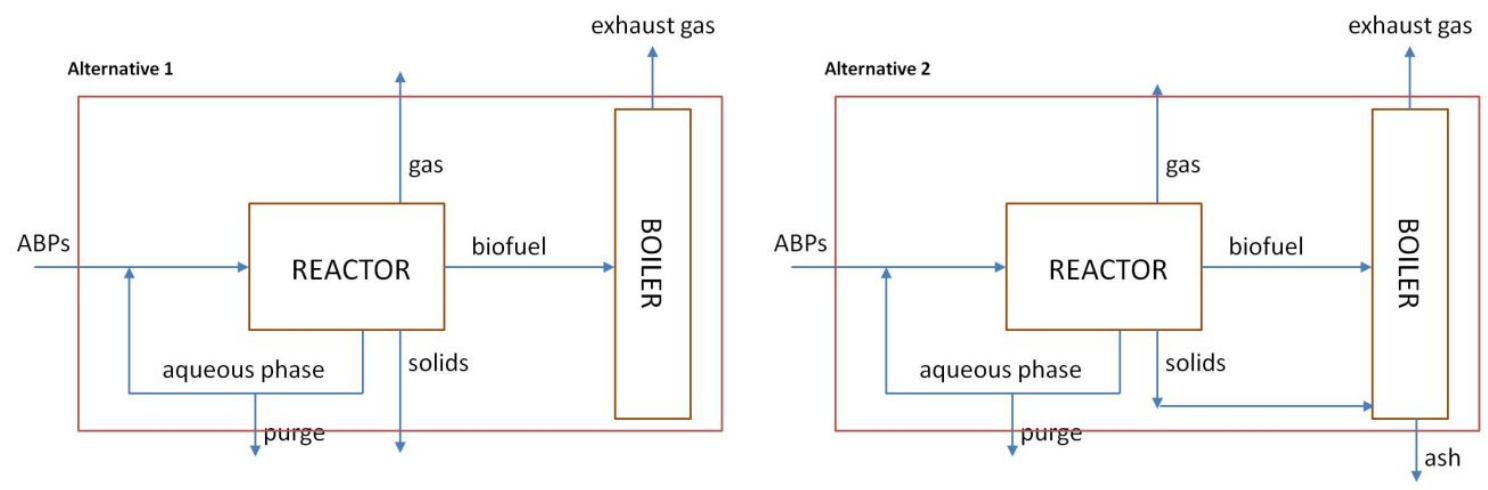


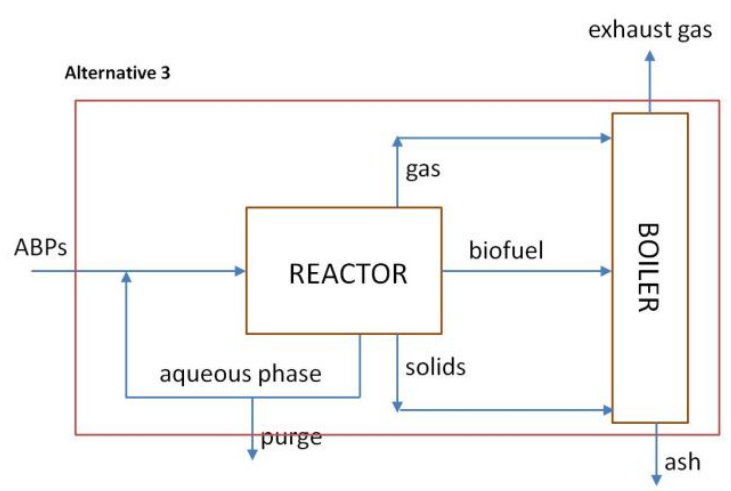

Figure 3. System boundaries diagrams for the alternatives studied

Therefore, three different alternatives have been proposed and analysed by the LCA:

case 1) combustion of the biofuel, considering the solids and the HTL gas fraction as waste; case 2) combustion of the biofuel and solids as fuels, and the emission of HTL gas fraction; case 3) combustion of the biofuel, solids and HTL gas fraction.

\subsection{Life cycle inventory ( $\mathrm{LCl})$ analysis}

Five burdens have been selected to develop the analysis of the LCI: HTL gas phase, combustion gases, aqueous phase, solids and electricity. Table 5 shows the total load assigned to each burden for each one of the three alternatives considered referred to the functional unit used in the present LCA. Appendix 4 (see Supporting information) details the components of the mass flows emitted in each case as well as the energy recovered from the combustion of the fuels. From the energy point of 
view, the combustion of solids increases the energy recovery in $3.4 \%$, while the value of HTL gas combustion is not significant. The effect of the initial raw material considered as a waste, and its transportation have been neglected. Taking into account the time scale used in this analysis and the general lifetime of the infrastructures, their contribution to the LCA has been also neglected.

Table 5. Life Cycle Inventory referred to the functional unit used (1 metric ton of $A B P)$.

\begin{tabular}{|l|c|c|c|}
\hline \multicolumn{1}{|c|}{ Burden } & $\begin{array}{c}\text { Biofuel } \\
\text { combustion }\end{array}$ & $\begin{array}{c}\text { Biofuel+solids } \\
\text { combustion }\end{array}$ & $\begin{array}{c}\text { Biofuel+solids+gas } \\
\text { combustion }\end{array}$ \\
\hline HTL Gas phase $(\mathrm{kg})$ & 12.1 & 12.1 & 11.9 \\
\hline Combustion gases $(\mathrm{kg})$ & 1525.4 & 2154.2 & 2154.6 \\
\hline $\begin{array}{l}\text { Aqueous phase (purge) } \\
(\mathrm{kg})\end{array}$ & 365.2 & 365.2 & 365.2 \\
\hline Solid (kg) demanded & 185.9 & 185.9 & 185.9 \\
\hline $\begin{array}{l}\text { Electricity } \\
(\mathrm{kWh})\end{array}$ & & $42.2(\mathrm{ash})$ & 42.2 (ash) \\
\hline
\end{tabular}

As can be seen, the gas fraction in Appendix 4 (Table A4.1) includes components from two different origins: components coming from the HTL gas fraction and combustion gases coming from the combustion of the fuels produced. The flow of combustion gases has been calculated from the elemental analysis of each fraction, 
considering the formation of $\mathrm{CO}_{2}, \mathrm{H}_{2} \mathrm{O}, \mathrm{NO}$ and $\mathrm{NO}_{2}$ (last two compounds in 95:5 ratio $^{34}$ ) in the combustion reactions.

The energy consumption includes the items commented on previously and shown in Table 3.

\subsection{Life cycle impact assessment (LCIA)}

The ReCiPe methodology ${ }^{35}$ has been used to transform the burdens of the $\mathrm{LCl}$ into environmental impact indicators. The mid-point level with a hierarchism perspective (H) has been initially selected. Eighteen impact subcategories were used in this analysis: terrestrial acidification (TAP), terrestrial ecotoxicity (TETP), freshwater eutrophication (FEP), freshwater ecotoxicity (FETP), marine eutrophication (MEP), marine ecotoxicity (METP), agricultural land occupation (ALOP), urban land occupation (ULOP), natural land transformation (NLTP), climate change (GWP), human toxicity (HTP), photochemical oxidant formation (POFP), ozone depletion (ODP), particulate matter formation (PMFP), ionising radiation (IRP), fossil depletion (FDP), metal depletion (MDP) and water depletion (WDP). The midpoint level allows comparing the contribution of each burden of the LCl (combustion gas, HTL gas 
phase, aqueous phase, solid fraction and energy) at each impact subcategory with a lower uncertainty ${ }^{36}$. Thus, the model developed includes the effect of the different burdens described previously in Tables 5 and Appendix 4 in proportion to their magnitude in mass or energy units. The corresponding environmental impact associated to the impact subcategory $\mathrm{k}$ is calculated as follows (eq 3 ):

$$
\text { Environmental Impact Indicator }(k)=\sum_{p}^{\text {Burdens }}\left(I F_{p, k}+L C I_{p}\right)
$$

where $L C I_{p}$ corresponds to the burden $p$ of the life cycle inventory and $I F_{p, k}$ is the impact factor of this burden $p$ for the impact subcategory $k$.

The hierarchism $(H)$ perspective has been selected instead of the individualist $(\mathrm{I})$ or egalitarian $(E)$ due to perspective $H$ is based on the most common policy principles with regards to time frame and other issues (e.g. 100 years for climate change or terrestrial acidification). On the other hand, perspective I is based on the short-term interest (e.g. 20 years time horizon for climate change or terrestrial acidification) and perspective $E$ is the most precautionary perspective (long-term interest, e.g. 500 years for climate change or terrestrial acidification). 
The impact factors applied in the analysis have been taken from the Ecoinvent Data Base $^{37}$ by using the allocation model at the point of substitution, and the updated ReCiPe characterization factors ${ }^{38}$ for the case of the direct emissions to the atmosphere. Table A4.2. (see Supporting Information. Appendix 4) lists the compounds detected experimentally and the substitute ones used in this LCIA.

In order to facilitate the interpretation of the environmental damage relevance, the ReCiPe metric also allows working at the end point level. This level of analysis aggregates the different impact subcategories on three main impact or damage categories in arbitrary units: human health, ecosystem diversity and resource availability. In this sense, the ReCiPe Endpoint $(H, A)$ level, i.e. by using the hierarchist $(\mathrm{H})$ perspective and the average $(\mathrm{A})$ weighting, has also been used to characterise the HTL process.

\section{LCA RESULTS AND DISCUSSION}

\subsection{Mid-point level analysis (individual subcategories)}

Figure 4 shows, for the three alternatives studied, the contribution of each one of the $\mathrm{LCl}$ burdens at each one of the mid-point level impact subcategories analysed. 
According to Figure 4, the impact caused by the HTL gases is negligible, independently of the impact category analysed, which is logical due to the low percentage of gas fraction generated in the process. As can be seen, electricity (energy consumption) mainly affects 8 subcategories: water, metal, fossil and ozone depletion, urban and agricultural land occupation, natural land transformation and ionising radiation. Gases resulting from the combustion are the main contribution in 5 subcategories: particulate matter formation, photochemical oxidant, human toxicity, climate change and terrestrial acidification. Obviously, these impacts are not due to the HTL process, but to the use of the fuels obtained. The maximum value of HTL gas phase/combustion gas ratio is $1.1 \%$ in the climate change subcategory. In the case of the climate change, if the $\mathrm{CO}_{2}$ emissions from the gas stream are considered as biogenic $\mathrm{CO}_{2}$ due to the fact that came from a biomass waste, and therefore as a neutral in the LCA, the corresponding contribution should be eliminated. In this case, the main contribution in climate change would be the energy consumption with a $99.89 \%$. Otherwise, its contributions are $7 \%$ or $4.8 \%$ depending on the waste combustion. 
If the aqueous phase purge were spilled out without any control, it would mainly affect the marine eutrophication and the marine, freshwater and terrestrial ecotoxicity. However, it must be taken into account that this phase is not a waste but could be a source of added value compounds, such as glycerine, or could potentially be used as a fertilizer (high water percentage with nitrogen-containing compounds) after the treatment needed. Thus for example, the use of lignocellulosic biofuel as fertilizer ${ }^{39}$ as well as the aqueous phase resulting from fermentation processes ${ }^{40}$ has been reported previously.

The main impact of the solids is on the freshwater eutrophication due to the presence of phosphorous in the ash, which is present independently of the solid treatment (combustion or not). Therefore, its discharge should be controlled to avoid any damage to the environment.

As is observed, the three alternatives led to very similar results and in none of the 18 impact subcategories studied, the combustion of the three fractions presents benefits compared to the combustion of only the liquid fuel. On the contrary, those five impact subcategories more affected by combustion gases show lower values when solids 
and HTL gas fraction are not burnt without appreciating any increase in the impact caused by these emissions. Only the marine eutrophication subcategory shows slight differences among the alternatives in the impact caused by the solids, due to the nitrogen content poured when this fraction is not burnt. In this case, the impact reduction of the combustion gases in alternative 1 is compensated by the impact increase of the solids, leading the three alternatives to similar results.

According to this analysis, the most environmentally friendly option seems to be the alternative where only biocrude is burnt since the combustion gases produce lower impact and no increase of the impact generated by the other burdens is detected.
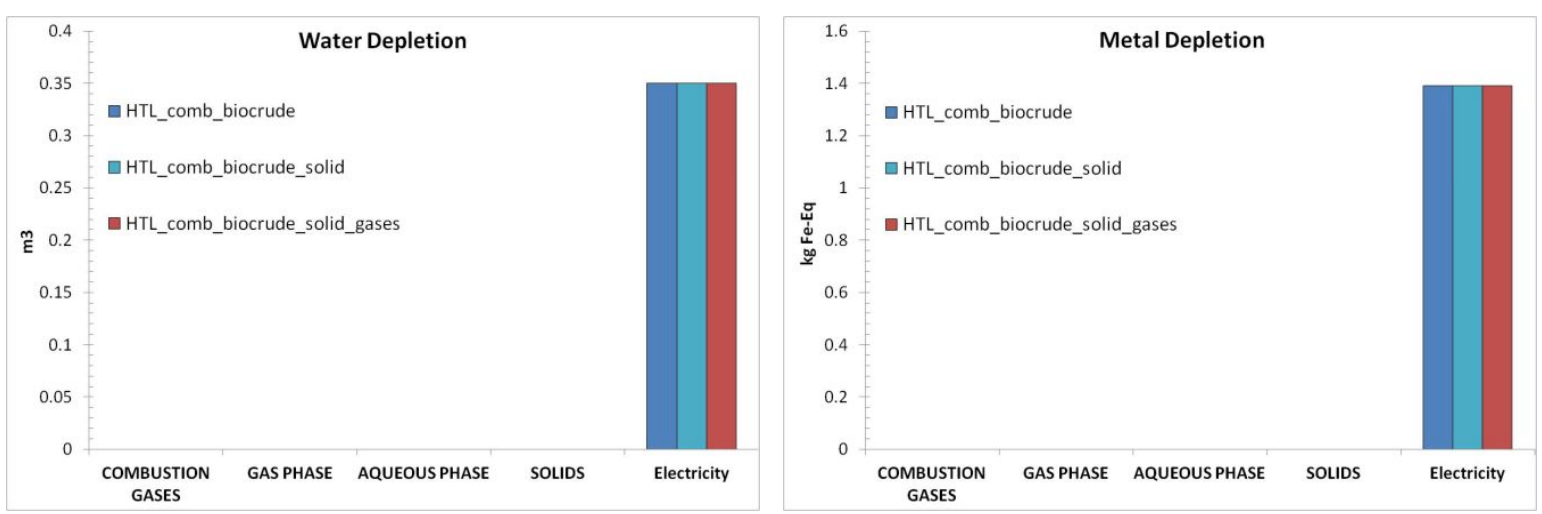

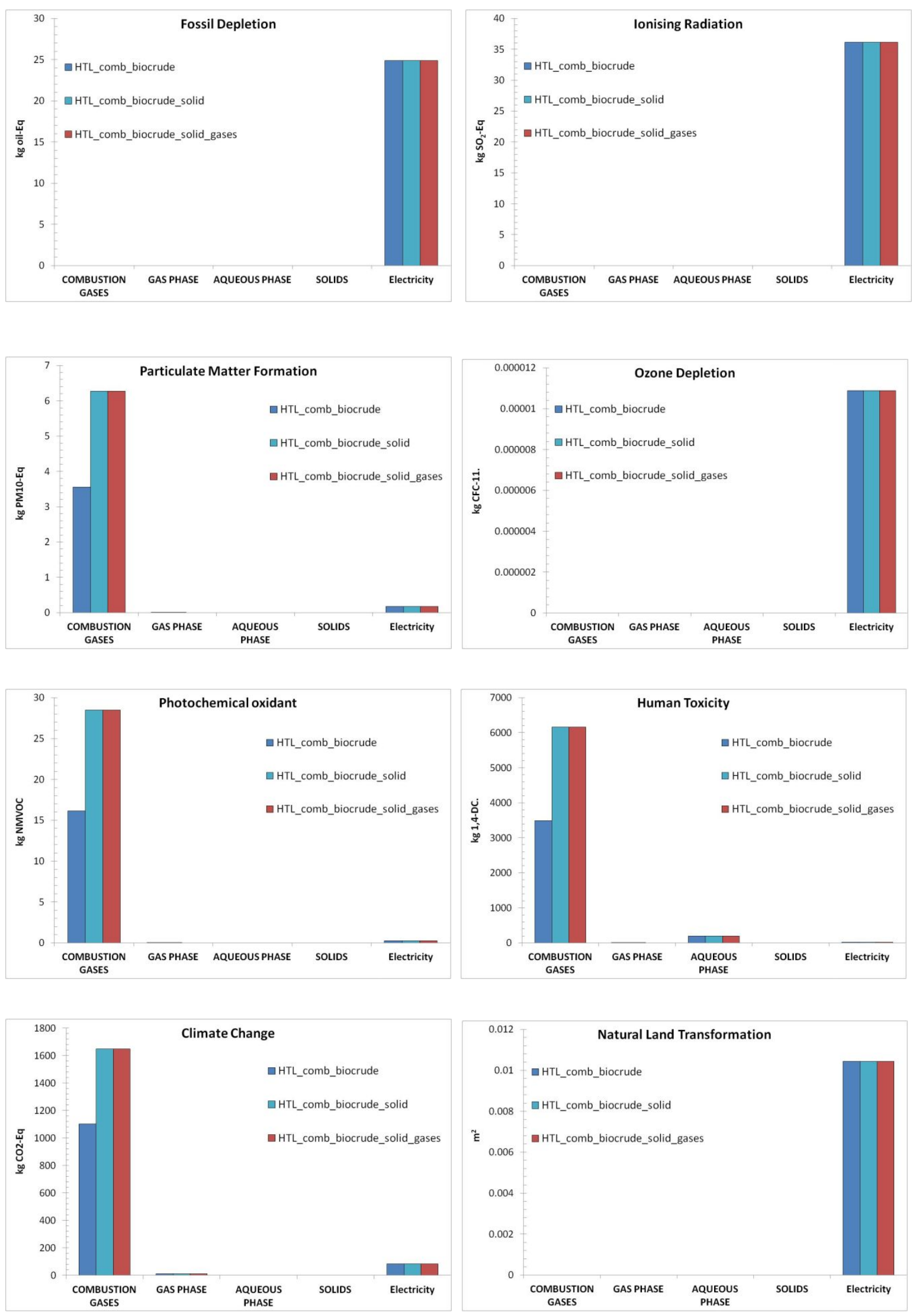

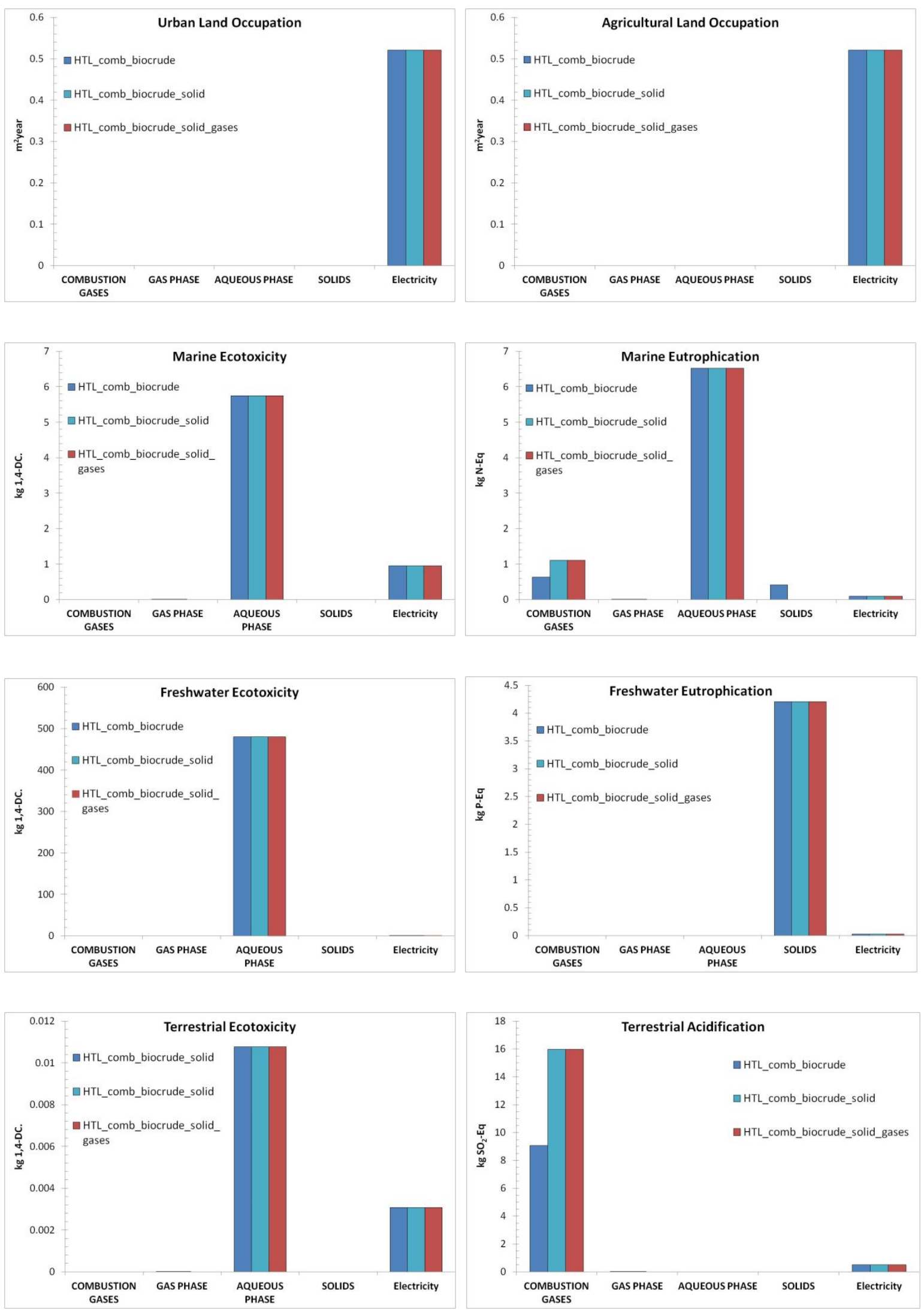
Figure 4. Contribution of the LCI burdens to the mid-point level impact subcategories analysed.

A more detailed analysis was performed by comparing the individual contribution of the components of the five LCl burdens by using a heat map. As an example, the map corresponding to the first alternative, where only the liquid biofuel was burnt, is presented in Figure 5. This figure allows visualising easily which components show the highest effect on each impact subcategory (in red colour). As can be seen, and as it was expected, in the group of combustion gases, $\mathrm{CO}_{2}(\# 4)$ stands out for its impact on the subcategory climate change while NO (\#1) stands out in other 4 subcategories: terrestrial acidification, human toxicity, photochemical oxidant formation and particulate matter formation. In the aqueous phase, 3 organic compounds $\quad$ (1,4-diaza-2,5-dioxobicycle[4.3.0]nonane $\quad$ (\#35), 2-methyl-9hydroxyphenalenone (\#46) and cholest-5-en-3-ol(3.beta.) (49)) together with the presence of nitrogen (\#50) standing out among others. The phosphorous content in the solid ash (\#52) is also remarkable. 
Thus, while Figure 4 analyses the impacts of the five burdens studied, Figure 5 breaks these burdens down into 53 components, which allows us to know what components generated in the process show the greatest negative impact on the environment.

In addition, Figure 6 compares the values of the global warning potential per kWh of energy produced from different sources. The data have been obtained from Ecoinvent Data Base 3.4, using the impact category 'climate change' with methodology $\mathrm{ReCiPe}$ at Midpoint $(\mathrm{H})$ level. The figure includes the values corresponding to the cases analysed in this paper. Due to the differences in the boundaries of the analyses, the comparison cannot be considered as totally accurate but it gives us a rough vision. As can be seen, the impact of the HTL process studied is closer to photovoltaic more than biogas, natural gas or municipal waste incineration, and obviously further than the fossil fuels. 


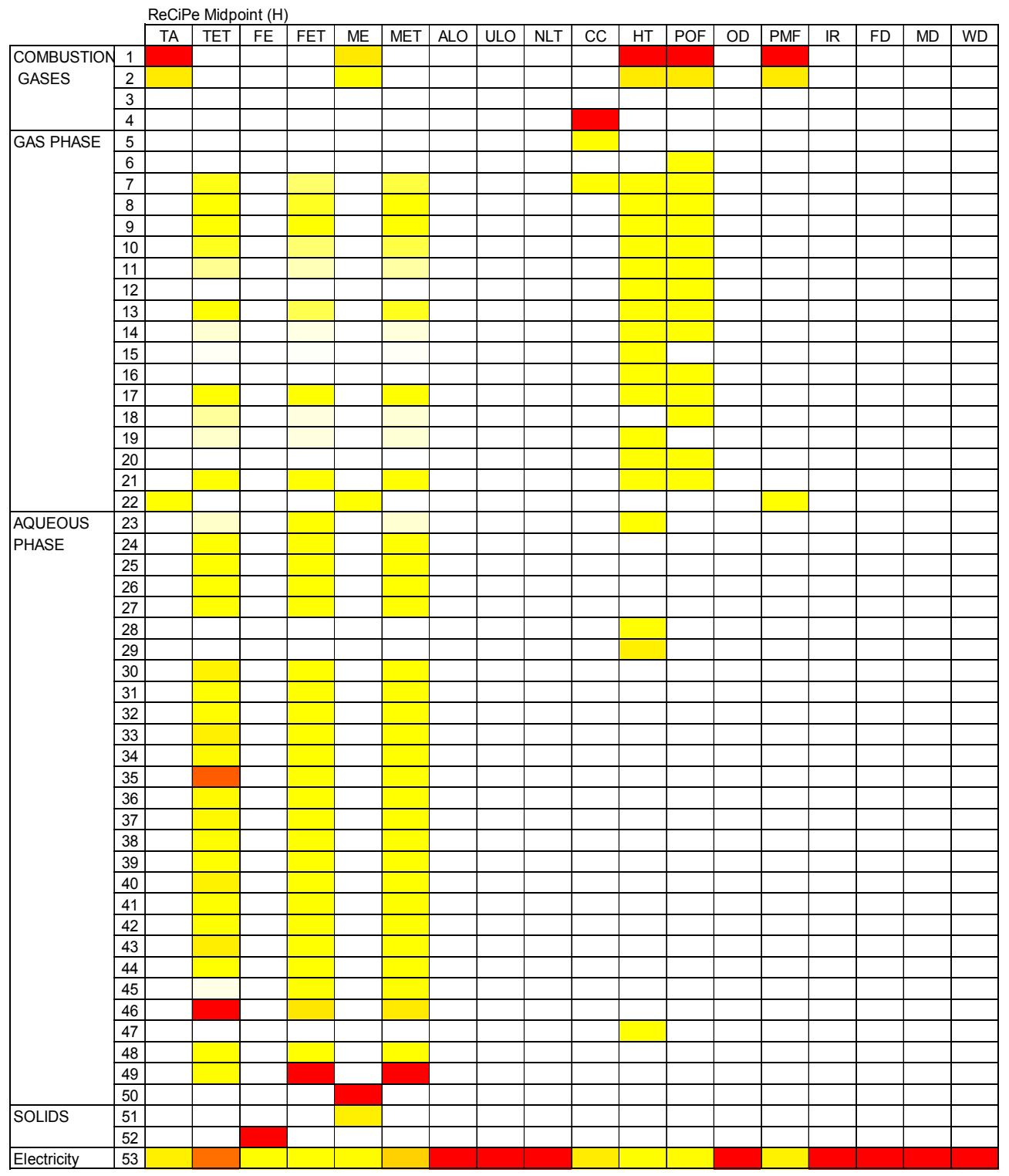

Figure 5. Heatmap of the contribution of the different compounds of the $\mathrm{LCl}$ (listed in

Appendix 4) to the impact subcategories, in the case of the HTL process considering

only the biofuel combustion (darker colors in the heatmap represent greater impacts).

Legend: TA: terrestrial acidification, TET: terrestrial ecotoxicity, FE: freshwater eutrophication, FET: freshwater ecotoxicity, ME: marine eutrophication, MET: marine ecotoxicity, ALO: agricultural land occupation, ULO: urban land occupation, NLT: natural land transformation, CC: climate change, HT: human toxicity, POF: photochemical oxidant formation, OD: ozone depletion, PMF: particulate matter formation, IR: ionising radiation, FD: fossil depletion, MD: metal depletion, WD: water depletion. 


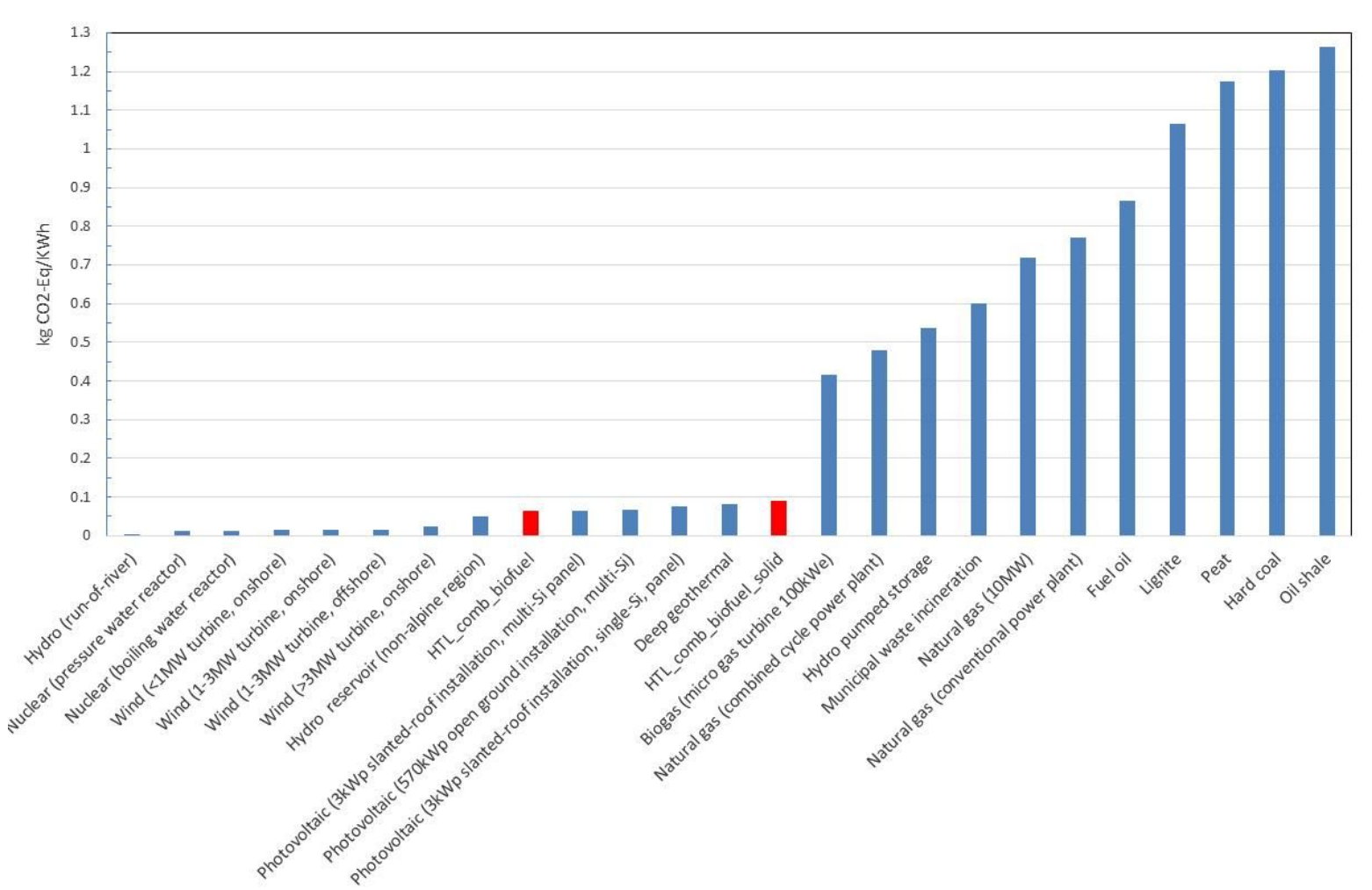

Figure 6. Comparison of the global warning potential of different energy sources.

\subsection{End point level analysis (aggregated categories)}

Figure 7 evaluates the damage caused on the environment by the processes studied, according to the end-point level $(\mathrm{H})$ analysis. This figure compares the results obtained for the three alternatives studied. As can be seen, there are not differences by burning 2 or 3 fractions, which means that the combustion of HTL gases hardly affects the environmental analysis since this phase is mainly formed by $\mathrm{CO}_{2}$. According to these results, the three alternatives affect the resource depletion at the same level while the alternative of burning only the liquid biofuel presents 
lower impacts on the human health and ecosystem quality categories. Table 6 shows the contribution (arbitrary points) of each burden at the three main damage categories. As was deduced from the mid-point level analysis, differences between alternatives only affect combustion gases (both values presented in the table).

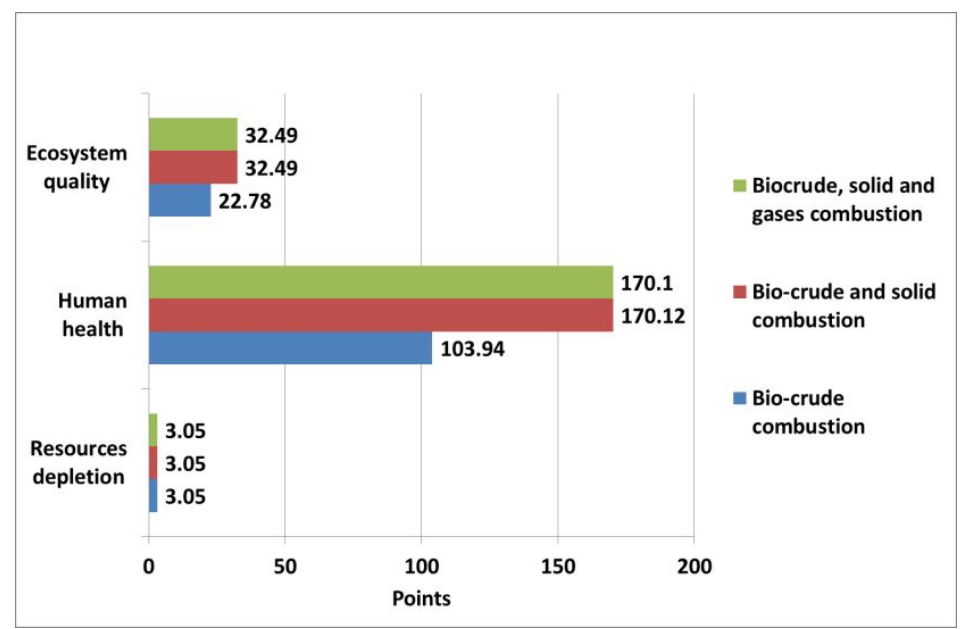

Figure 7. Endpoint level analysis $(H, A)$. Arbitrary points -normalized and weighted by using the recommended average $(A)$ weights.

Table 6. Contribution of each burden at the endpoint damage categories

\begin{tabular}{|l|c|c|c|}
\hline & $\begin{array}{c}\text { Resource } \\
\text { depletion }\end{array}$ & $\begin{array}{c}\text { Human } \\
\text { health }\end{array}$ & $\begin{array}{c}\text { Ecosystem } \\
\text { quality }\end{array}$ \\
\hline Combustion gas & - & $\begin{array}{c}97.3^{\text {(case1) }} \\
163.5^{\text {(case2-3) }}\end{array}$ & $\begin{array}{c}19.4^{\text {(case1) }} \\
29.1 \text { (case2-3) }\end{array}$ \\
\hline HTL gas phase & - & 0.34 & 0.21 \\
\hline Aqueous phase (purge) & - & 2.72 & 0.92 \\
\hline Solid & - & - & 0.41 \\
\hline Electricity & 3.05 & 3.58 & 1.80 \\
\hline
\end{tabular}




\section{CONCLUSIONS}

The objective proposed at the beginning of this work has been confirmed. The comparison of two thermochemical processes, pyrolysis and hydrothermal liquefaction, as alternatives for obtaining biofuel from animal by-products has been carried out. The selection of hydrothermal liquefaction process with a water content of around $60 \%$ and recycling the aqueous phase is the most favourable option. This configuration avoids the drying step of the pyrolysis and reduces the water consumption of the basic HTL process, which implies the reduction of the total energy demanded.

The life cycle assessment of the alternative selected has been developed using the ReCiPe 2008 methodology. The combustion of the fuel fractions obtained (liquid biofuel, solid and gas fractions) has been included in the assessment. Five environmental burdens: combustion gases, HTL gas phase, aqueous phase (purge), solid fraction and electricity consumption have been analysed. Regarding at the midpoint level, which analyses individually 18 damage subcategories, the electricity demanded mainly impacts on 8 subcategories associated with land occupation and 
transformation, resource depletion and radiation. Combustion gases affect 5 damage subcategories and they are the main contribution at 2 of the aggregated endpoint damage categories: human health and ecosystem quality. Obviously, these gases are not generated in the HTL process but in the combustion of the fuels produced. Since the energy recovered by the combustion of HTL gas or solid fractions is low, no benefits are obtained with the combustion of these fractions. In order to improve the sustainability of the process, the use of subproducts must be studied, especially nitrogen and phosphorous content in solids and the use of aqueous phase purge . as fertilizer or source of added value compounds taking into account its content on glycerine and other interesting compounds.

\section{- ASSOCIATED CONTENT}

\section{Supporting Information}

In Appendix 1, experimental data obtained in the HTL process with aqueous phase recycled have been presented. In Appendix 2, the scale-up of the mass flow of the streams involved in the HTL process with aqueous phase recycled as well as in the pyrolysis process have been shown. Appendix 3 shows the calculation of energy and 
water consumptions in the process studied referred to a feed flowrate of $5000 \mathrm{~kg} / \mathrm{h}$ of ABPs. Additionally, Appendix 4 details the $\mathrm{LCl}$ burdens for the different alternatives analyzed, and includes all the experimental compounds detected and the substitute ones used in the LCIA.

\section{- AUTHOR INFORMATION}

\section{Corresponding Author}

*Corresponding author: ja.labarta@ua.es, Tel.: +34 96590 3867. ORCID@:

http://orcid.org/0000-0002-4870-2031.

\section{Author Contributions}

The manuscript was written through contributions of all authors. All authors have given approval to the final version of the manuscript.

\section{- ACKNOWLEDGEMENTS}

The research leading to these results has received funding from the European Community's 7th Framework Programme (FP7-2007-2013) under Grant Agreement No. 603986 and from the Spanish «Ministerio de Economía, Industria y 
Competitividad» under the project CTQ2016-77968-C3-2-P (FEDER, UE). We also thank GreenE Waste To Energy, S.L. for their collaboration in the development of this work.

\section{- REFERENCES}

(1) AMSA. Composition on meat-water, carbohydrates, minerals and vitamins. Am.

Meat Sci. Assoc.: Champaign, 2015.

(2) Leon, M.; Garcia, A.N.; Marcilla, A.; Martinez-Castellanos, I.; Navarro, R.;

Catala, L. Thermochemical conversion of animal by-products and rendering products. Waste Manag. 2018, 73, 447.

(3) FP7-Pilot ABP. No. 603986. Pilot plant for environmentally friendly animal by products industries. Seventh Framework Programme, European Commission. 2014.

(4) Marculescu, C.; Alexe, F. Assessing the power generation solution by thermalchemical conversion of meat processing industry waste. Energy Procedia. 2014, 50, 738.

(5) Zheng, J.L.; Kong, Y.P. Hydrothermal liquefaction of waste meat for liquid fuel. J. 
Chem. Ind. Eng. 2014. 65, 4150.

(6) Zheng, J.L.; Zhu, M.Q.; Wu, H.T. Alkaline hydrothermal liquefaction of swine carcasses to bio-oil. Waste Manag. 2015, 43, 230.

(7) Yin, S.; Dolan, R.; Harris, M.; Tan, Z. Subcritical hydrothermal liquefaction of cattle manure to bio-oil: Effects of conversion parameters on bio-oil yield and characterization of bio-oil. Bioresour. Technol. 2010, 101, 3657.

(8) Food safety European Commission website. Animal by-products. https://ec.europa.eu/food/safety/animal-by-products_en (accessed 30.10.19)

(9) Liu, X.; Saydah, B.; Eranki, P.; Colosi, L.M.; Greg Mitchell, B.; Rhodes, J.; Clarens, A.F. Pilot-scale data provide enhanced estimates of the life cycle energy and emissions profile of algae biofuels produced via hydrothermal liquefaction. Bioresour. Technol. 2013, 148, 163.

(10) Orfield, N.D.; Fang, A.J.; Valdez, P.J.; Nelson, M.C.; Savage, P.E.; Lin, X.N.; Keoleian, G.A. Life cycle design of an algal biorefinery featuring hydrothermal liquefaction: effect of reaction conditions and an alternative pathway including 
microbial regrowth. ACS Sustain. Chem. Eng. 2014, 2, 867.

(11) Ponnusamy, S.; Reddy, H.K.; Muppaneni, T.; Downes, C.M.; Deng, S. Life cycle assessment of biodiesel production from algal bio-crude oils extracted under subcritical water conditions. Bioresour. Technol. 2014, 170, 454.

(12) Zhu, Y.; Biddy, M.J.; Jones, S.B.; Elliott, D.C.; Schmidt, A.J. Techno-economic analysis of liquid fuel production from woody biomass via hydrothermal liquefaction (HTL) and upgrading. Appl. Energy. 2014, 129, 384.

(13) Benavente, V.; Fullana, A.; Berge, N.D. Life cycle analysis of hydrothermal carbonization of olive mill waste: Comparison with current management approaches.

J. Clean. Prod. 2017, 142, 2637.

(14) Iribarren, D.; Peters, J.F.; Dufour, J. Life cycle assessment of transportation fuels from biomass pyrolysis. Fuel. 2012, 97, 812.

(15) Rogers, J.G.; Brammer, J.G. Estimation of the production cost of fast pyrolysis bio-oil. Biomass and Bioenergy. 2012, 36, 208.

(16) Bennion, E.P.; Ginosar, D.M.; Moses, J.; Agblevor, F.; Quinn, J.C. Lifecycle 
assessment of microalgae to biofuel: Comparison of thermochemical processing pathways. Appl. Energy. 2015, 154, 1062.

(17) Chan, Y.H.; Tan, R.R.; Yusup, S.; Lam, H.L.; Quitain, A.T. Comparative life cycle assessment (LCA) of bio-oil production from fast pyrolysis and hydrothermal liquefaction of oil palm empty fruit bunch (EFB). Clean Technol. Environ. Policy. 2016, 18(6), 1759.

(18) Delrue, F.; Li-Beisson, Y.; Setier, P.A.; Sahut, C.; Roubaud, A.; Froment, A.K.; Peltier, G. Comparison of various microalgae liquid biofuel production pathways based on energetic, economic and environmental criteria. Bioresour. Technol. 2013, 136, 205.

(19) Leon, M.; Marcilla, A.F.; García, A.N. Hydrothermal liquefacction (HTL) of animal by-products: Influence of operating conditions. Waste Manag. 2019, 99, 4959.

(20) Marcilla, A.; León, M.; García, A.N.; Bañón, E.; Martínez, P. Upgrading of tannery wastes under fast and slow pyrolysis conditions. Ind. Eng. Chem. Res. 2012, $51,3246-3255$ 
(21) Pielsticker, S.; Schlögel, K.; Kreitzberg, T.; Hatzfeld, O.; Kneer, R. Biomass pyrolysis kinetics in a fluidized bed reactor: Measurements and plausibility verification for reaction conditions. Fuel. 2019, 254, 115589.

(22) Cryogenic Liquid Nitrogen Plant. Cangas Systems Company Limited. 2018.

(23) King, J.W.; Holliday, R.L.; List, G.R. Hydrolysis of soybean oil in a subcritical water flow reactor. Green Chem. 1999, 1(6), 261.

(24) Meat and bone crushing machine. Runxiang Machinery Equipment Co. Ltd., 2018.

(25) Industrial, sanitary, sterile agitators, ATEX version. VAK KIMSA S.A. 2018.

(26) Fernández González, J.; Gutiérrez Martín, F.; Del Río González, P.; San Miguel Alfaro, G.; Bahillo Ruiz, A.; Sánchez Hervás, JM.; Ballesteros Perdices, M.; Vázquez Minguela, JA.; Rodríguez Antón, LM.; Aracil Mira, J. Tecnologías para el uso y transformación de biomasa energética; Ed. Mundi-Prensa: Madrid, 2015.

(27) Li, C.; Yang, X.; Zhang, Z.; Zhou, D.; Zhang, L.; Zhang, S. , Chen, J. Hydrothermal liquefaction of desert shrub salix psammophila to high value-added 
chemicals and hydrochar with recycled processing water. Bioresources. 2013, 8, 2981.

(28) Sinnott, R.K.; Towler, G. Chemical engineering design; 5th ed. ButterworthHeinemamn: Oxford. 2009

(29) Europe's water in figures. An overview of the European drinking water and waste water sectors. The European Federation of National Associations of Water Services. 2017. .

(30) Eurostat. Energy, transport and environment statistics. 2019.

(31) Clift, R. Sustainable development and its implications for Chemical Engineering. Chem Eng Sci. 2006, 61 (13), 4179.

(32) ISO 14040. Environmental Management - Life Cycle Assessment - Principles and Framework, International Organization for Standardization (ISO): Geneva, Switzerland. 2006.

(33) ISO 14044. Environmental Management - Life Cycle Assessment Requirements and guidelines; International Organization for Standardization (ISO): 
Geneva, Switzerland. 2006.

(34) DieselNet, 2018. Gaseous Emissions [WWW Document]. URL: https://www.dieselnet.com/tech/emi_gas.php (accessed 7.17.18).

(35) Goedkoop, M.; Heijungs, R.; Huijbregts, M.; De Schryver, A.; Struijs, J.; Van Zelm, R. ReCiPe 2008: a life cycle impact assessment method which comprises harmonised category indicators at the midpoint and endpoint levels. Report I: Characterisation; National Institute for Public Health and the Environment (RIVM): Bilthoven, The Netherlands, 2009.

(36) Hauschild, M. Z.; Huijbregts, M. A. J.(Eds.). Life cycle impact assessment, Springer: Netherlands, Dordrecht, 2015.

(37) ECOINVENT ${ }^{\circledR}$. The Life Cycle Inventory Data. In 3.4 ed.; Swiss Centre for Life Cycle Inventories: Dübendorf, Switzerland, 2017.

(38) RIVM. LCIA: the ReCiPe Model 2008 characterization factors (Version 1.11December 2014). The Dutch National Institute for Public Health and the Environment. 2018. 
(39) Czernik, S.; Bridgwater A.V. Overview of applications of biomass fast

pyrolysis oil. Energ Fuel. 2004, 18, 590-598.

(40) Gómez Millán, G. Desarrollo de biorrefinerías en el mundo. Ciencia y Desarrollo. May, 2015, 35-59.

\section{LIST OF FIGURE CAPTIONS}

Figure 1. Scheme of a continuous HTL process.

Figure 2. Scheme of a continuous pyrolysis process.

Figure 3. System boundaries diagrams for the alternatives studied.

Figure 4. Contribution of the $\mathrm{LCl}$ burdens to the mid-point level impact subcategories analysed.

Figure 5. Heatmap of the contribution of the different compounds of the LCl (listed in Appendix 4) to the impact subcategories, in the case of the HTL process considering only the biofuel combustion.

Figure 6. Comparison of the global warning potential of different energy sources.

Figure 7. Endpoint level analysis $(H, A)$. Arbitrary points -normalized and weighted by using the recommended average (A) weights. 


\section{- LIST OF TABLE CAPTIONS}

Table 1. Operational parameters of thermal processes studied.

Table 2. Yield of fractions obtained.

Table 3. Water and energy consumptions in HTL and pyrolysis processes referred to a feed flowrate of $5000 \mathrm{~kg} / \mathrm{h}$ of ABPs.

Table 4. Cost comparison of the HTL and pyrolysis processes.

Table 5. Life Cycle Inventory referred to the functional unit used (1 metric ton of ABP).

Table 6. Contribution of each burden at the endpoint damage categories. 


\section{Table of Contents Graphic}

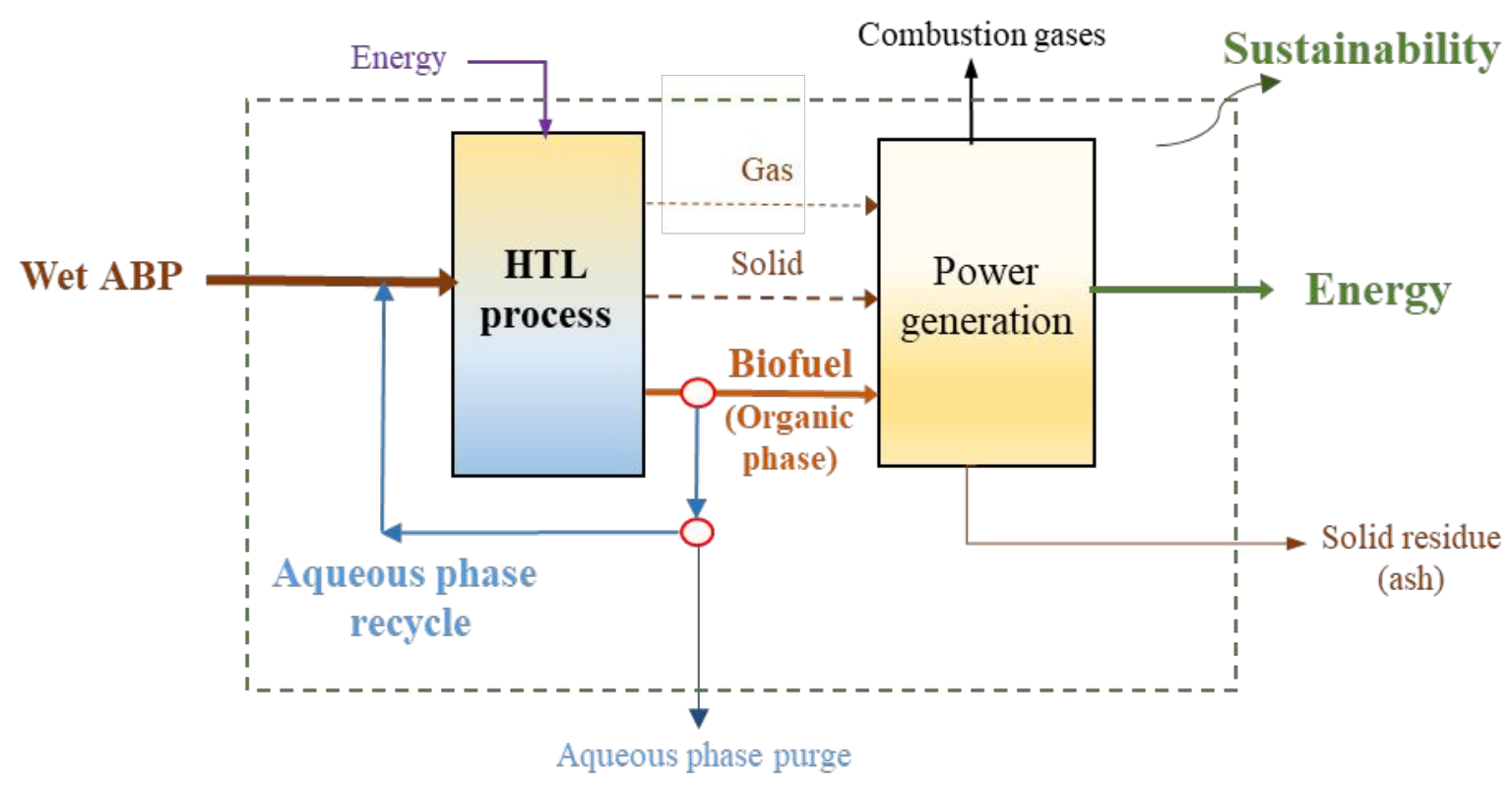

